\title{
HISTOMORPHOMETRIC ASSESSMENT OF WHARTON'S JELLY AREA IN NORMAL AND PRE-ECLAMPTIC PREGNANCIES AND ITS CORRELATION WITH PLACENTAL WEIGHT
}

\author{
Ankit Jain ${ }^{1}$, Prateek Shrivastava ${ }^{* 2}$, Rashmi Jain ${ }^{3}$. \\ ${ }^{1}$ M.S., Assistant Professor, Department of Anatomy, Shyam Shah Medical College, Rewa (M.P.), \\ India. \\ ${ }^{* 2}$ Resident, Department of Anatomy, Mahatma Gandhi Memorial Medical College, Indore (M.P.), \\ India. \\ ${ }^{3}$ M.D., Assistant Professor, Department of Pathology, Shyam Shah Medical College, Rewa (M.P.), \\ India
}

\section{ABSTRACT}

Introduction: Fetal capability to grow in utero depends on placental development and function. The goal of this study was to appraise the effects of hypertension on placental weight and Wharton's jelly area (WJA); and correlate them in normal and pre-eclamptic pregnancies.

Material and Methods: Eighty placentae along with umbilical cord divided into forty each of normotensive and pre-eclamptic pregnancies were studied. The cross-sectional area of the umbilical cord and vessels area was measured with the help of vernier scale and ocular micrometer respectively. WJA was calculated by deduction of the vascular area from the umbilical cord area. Placental weight was recorded by using a weighing machine and correlated with the WJA.

Results: In the present study, mean placental weight was $445.45 \pm 40.31$ grams and WJA was $35.28 \pm 8.42 \mathrm{~mm}^{2}$ in the normal group. Whereas, in the pre-eclamptic group, mean placental weight was $408.95 \pm 47.15$ grams and WJA was $29.04 \pm 8.09 \mathrm{~mm}^{2}$. Mean placental weight and WJA was significantly lower in the pre-eclamptic group. A significant positive correlation was found between WJA and placental weight $(r=0.710, p<0.0001)$ in normal group and $(r=0.764, p<0.0001)$ in pre-eclamptic group.

Conclusion: Pre-eclampsia is associated with reducing placental weight and WJA. Low WJA may hamper the fetal growth. The current study shows a strong positive correlation between WJA and placental weight. So, the awareness of this correlation will be helpful in the early observation of placental insufficiencies and provide sufficient information to take additional care in such conditions.

KEY WORDS: Wharton's jelly, Placental weight, Pre-eclampsia, Umbilical cord.

Address for Correspondence: Dr. Prateek Shrivastava, Resident, Department of Anatomy, Mahatma Gandhi Memorial Medical College, Indore (M.P.), India. Telephone: +919827570908.

E-Mail: ankitjain6285@gmail.com

Access this Article online

Quick Response code

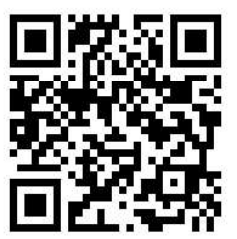

DOI: 10.16965/ijar.2019.221

Journal Information

\section{International Journal of Anatomy and Research}

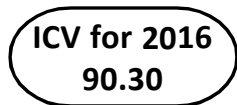
ISSN (E) 2321-4287 | ISSN (P) 2321-8967 https://www.ijmhr.org/ijar.htm DOI-Prefix: https://dx.doi.org/10.16965/ijar

\section{(cc) $\mathrm{EY}-\mathrm{Mb}-\mathrm{si}$}

\section{Article Information}

Received: 05 May 2019

Peer Review: 05 May 2019

Revised: None
Accepted: 10 Jun 2019

Published (O): 05 Jul 2019

Published (P): 05 Jul 2019

\section{INTRODUCTION}

During intrauterine life, all the mandatory nutrients required for growth and development of fetus passes through the placenta and umbilical cords. Therefore, proper examination of the placenta and umbilical cord gives an idea 
about the fetal consequences when it was in the mother's womb.

Placenta undergoes different changes in structure, function, shape, and weight continuously, during its development throughout the gestation [1]. Complicated pregnancies like gestational diabetes or hypertension have an unhealthy impact on the placenta both macroscopically and microscopically. Pre-eclampsia is in concomitant with increase vascular resistance which may lead to reduce uteroplacental perfusion. As a result of decrease uteroplacental perfusion, fetal hypoxia and intrauterine growth retardation can become inescapable [2].

Fetal well-being depends upon the structure and function of the umbilical cord because feto-maternal blood flow is established by vessels within the cord. The umbilical cord vessels are cushioned by a special type of mucous connective tissue, known as Wharton's jelly, which is derived from the mucoid degeneration of primary mesodermal cells of the connecting stalk [3]. Wharton's jelly consists of the spongy network of interlacing collagen fibers that encases the umbilical vessels [4]. It contains myofibroblasts immersed in an extracellular matrix, primarily composed of glycosaminoglycans and proteoglycans [5]. The most abundant glycosaminoglycan is hyaluronic acid [6], which forms a hydrated gel around the collagen fibrils and maintains the tissue architecture of the umbilical cord [7]. So, the main function of Wharton's jelly is the protection of the umbilical blood vessels. Modifications in the composition of Wharton's jelly have been narrated in some pathological conditions such as fetal distress [8], maternal hypertension [9] and gestational diabetes [10]. Pre-eclampsia is associated with the reduced gelatinous activity, expression of insulin-like growth factor1 binding protein [9] and cathepsin D activity [11]. In such pregnancies, Wharton's jelly areas are reduced as compared to normal pregnancies $[12,13]$.

The motive of this study was to evaluate the effects of hypertension on placental weight and area of the Wharton's jelly; and to determine the correlation between Wharton's jelly area and placental weight in both normal and pre-eclamptic pregnancies.

\section{MATERIALS AND METHODS}

The study was carried out in the Department of Anatomy and Department of Obstetrics and Gynaecology, Gandhi Medical College, Bhopal (M.P). Eighty placentae along with umbilical cord collected from pregnant women who delivered in Sultania Zanana Hospital associated with G.M.C. Bhopal, after informed consent and due permission from the institutional ethics committee. Women were diagnosed with preeclampsia if they had systolic BP $\geq 140 \mathrm{mmHg}$ and diastolic $B P \geq 90 \mathrm{mmHg}$ measured on two or more occasions at least $4 \mathrm{hrs}$ apart after the $20^{\text {th }}$ week of gestation with proteinuria [14]. Proteinuria was considered present when there was a urine dipstick value of at least $1+(>30 \mathrm{mg} /$ dl) on two separate occasions at least 6 hours apart. On this basis, subjects were divided into two groups. Group I consist of placentae along with umbilical cord obtained from normal pregnant women $(n=40)$ with gestational age 37-40 weeks. Group II consisted of placentae along with umbilical cord obtained from pre- eclamptic women $(n=40)$. Patients with diabetes mellitus, essential hypertension, renal disorders, anemia and other illness associated with pregnancy were excluded from this study.

The mothers and their neonates identified for this study were given code numbers and studied at the hospital. The placentae were collected soon after their expulsion and placental weight was recorded using the weighing machine. After delivery, appearance, pulse, grimace, activity, and respiration rate (APGAR) of the newborn was recorded.

In all cases, segments of umbilical cord were obtained at $2 \mathrm{~cm}$ distance from the placental side, of the thickness of approximately $4-5 \mathrm{~mm}$ were routinely processed for paraffin embedding, sectioning, and $\mathrm{H}$ \& E staining. Two diameters from each histological section of umbilical cord were measured at a right angle, by using vernier scale on the stage of the microscope. The diameters of each blood vessel cross section were obtained in the same way, but vessels diameters were done by an ocular micrometer.

Total cord area, Jelly area, and total vessel area were calculated for each cord by the formulae 
given below:

1. $A=\pi D_{1} D_{2} / 4$ Where $A$ is area and $D$ is the diameter.

2. Total vessel area $=$ (Total area of artery $1+$ Total area of artery $2+$ Total area of a vein) in cross-section.

3. Jelly area $=($ Total umbilical cord area - Total vessels area) in cross-section.

Standardizations of the methods: All measurements were taken by using a $4 \mathrm{X}$ magnification of the objective lens. The measurements which were taken from the vernier scale on the stage of the microscope, shows the real size of the sample because it is not affected by the magnification of the microscope.

The measurements which were taken by using ocular micrometer are the magnified value of the objective lens. The reticle is mounted in the eyepiece, which is magnified by the objective lens. Such as a real particle with a diameter of $1 \mathrm{~mm}$ at the microscope stage, when viewed with $4 \mathrm{X}$ objective lens will appear as $4 \mathrm{~mm}$ diameter on the reticle. Hence such magnifications have to be taken into account while calculating real measurements.

Size of a sample displayed on reticle $=$ Sample 'Real Size' X 'Magnification of Objective lens'

Statistical analysis of data was performed by using Statistical Package for Social Sciences (SPSS) version 15.0 (Chicago, IL). The values of continuous variables were presented as mean values \pm standard deviation. Correlation between the parameters was analyzed using Pearson's correlation coefficient. The significance of differences between group parameters was analyzed by Student's t-test and differences were considered significant if $p<0.05$.

\section{RESULTS}

Gestational age was significantly lower in the pre-eclamptic group as compared to the normal group. In the normal group, mean placental weight was 445.45 grams, whereas in the pre-eclamptic group, mean placental weight was 408.95 grams. The mean placental weight was significantly lower in the pre-eclamptic group as compared to the normal group. In-turn, APGAR scores in the pre-eclamptic group were found to be significantly low [Table-1].
Table 1: Relationship of various parameters between normal and pre-eclamptic pregnancies.

\begin{tabular}{|c|c|c|c|c|}
\hline S.No. & Parameters & Normal $(\mathrm{n}=40)$ & $\begin{array}{c}\text { Pre-eclamptic } \\
(\mathrm{n}=40)\end{array}$ & P value $^{\mathrm{a}}$ \\
\hline 1 & Gestational age (weeks) $^{*}$ & $38.02 \pm 1.32$ & $36.17 \pm 0.93$ & $0.0001^{\mathrm{b}}$ \\
\hline 2 & Placental weight (grams)* & $445.45 \pm 40.31$ & $408.95 \pm 47.15$ & $0.0014^{\mathrm{b}}$ \\
\hline 3 & APGAR score* & $8.07 \pm 1.07$ & $6.6 \pm 0.98$ & $0.0001^{\mathrm{b}}$ \\
\hline 4 & Wharton's jelly area $\left(\mathrm{mm}^{2}\right)^{*}$ & $35.28 \pm 8.42$ & $29.04 \pm 8.09$ & $0.0039^{\mathrm{b}}$ \\
\hline
\end{tabular}

*Parameters were expressed as mean value \pm standard deviation;

a. p-values were calculated by using Student's t-test. $p \leq 0.05$ was considered significant. b. Statistically significant.

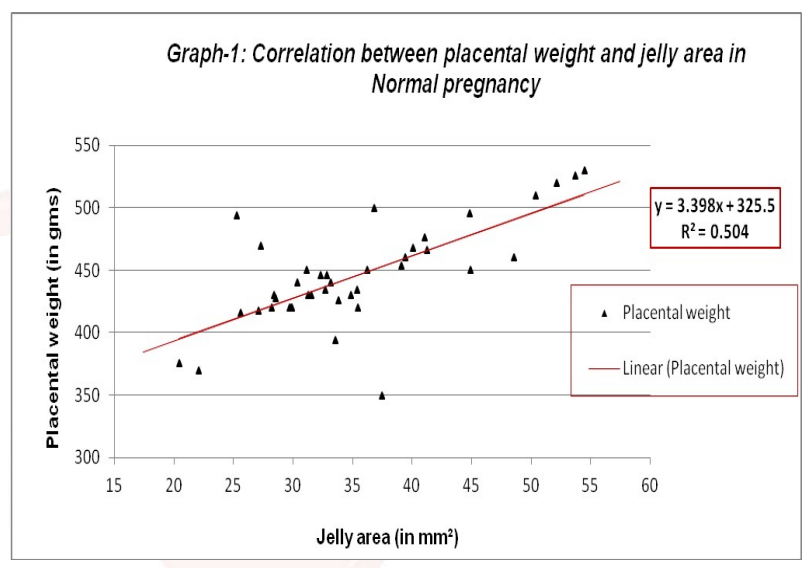

Graph-2: Correlation between placental weight and jelly area in Preeclamptic pregnancy

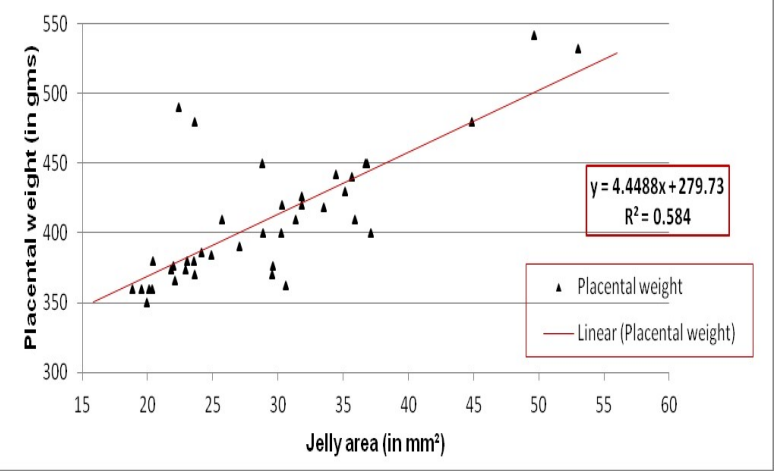

Histomorphometric analysis of umbilical cord show mean Wharton's jelly area was $35.28 \pm$ $8.42 \mathrm{~mm}^{2}$ in the normal group and $29.04 \pm 8.09$ $\mathrm{mm}^{2}$ in the pre-eclamptic group. WJA was significantly lower in the pre-eclamptic group as compared to the normal group [Table-1].

In the control group, there was a significant moderate positive correlation (Pearson correlation coefficient $r=0.710, p<0.0001$ ) between the placental weight and Wharton's jelly area. From the Graph-1, it is clear that the higher the value of the jelly area is associated with the higher the value of placental weight. The linear 
relationship is expressed by the following equation:

$y=3.398(x)+325.5$

Where $x$ is the jelly area in $\mathrm{mm}^{2}$ and $y$ is the placenta weight in grams. The estimator of the slope is given by $+3.398 \mathrm{gm} / \mathrm{mm}^{2}$ and the estimator of its intercept is given by $+325.5 \mathrm{gm}$. The interpretation of the slope of the regression line is that on average, an increase jelly area of $10 \mathrm{~mm}^{2}$ in control group is accompanied by an increase placental weight of $33.98 \mathrm{gm}$.

In the pre-eclamptic group, a significant strong positive correlation $(r=0.764, p<0.0001)$ was found between placental weight and jelly area. For the pre-eclamptic group [Graph-2], the relationship between placental weight and the jelly area is given by the following equation:

$y=4.448(x)+279.7$

Where $x$ is the jelly area in $\mathrm{mm}^{2}$ and $y$ is the placental weight in grams. The estimator of the slope is given by $+4.448 \mathrm{gm} / \mathrm{mm}^{2}$ and the estimator of its intercept is given by $+279.7 \mathrm{gm}$. The interpretation of the slope of the regression line is that on average, an increase jelly area of $10 \mathrm{~mm}^{2}$ in the pre-eclamptic group is accompanied by an increase placental weight of $44.48 \mathrm{gm}$. A test of linearity of the relationship between placental weight and the jelly area is statistically significant in both normal and pre-eclamptic group.

\section{DISCUSSION}

Placenta and umbilical cord being a fetal organ share the same stress and strain, to which the fetus is exposed during intrauterine life. Thus any disease process affecting the mother and fetus also has a great impact on placenta and umbilical cord [15]. Complicated diseases are metabolic in nature and they affect the placental efficiency and function. The feto-placental unit was adversely affected in pre-eclampsia. Due to placental insufficiency in pre-eclampsia, fetal growth was also affected [16]. Das B. et $a l$, observed that Placental weight was significantly reduced where the duration of hypertensive disorders was prolonged. A significant increase in the incidence of intrauterine growth retardation and still birth was found with the lower placental weight [2]. In the present study, we found that mean placental weight were significantly lower in the pre-eclamptic group [Table-1], which is similar to the observation of earlier researchers $[17,18]$.

Wharton's jelly is a metabolic active tissue involved in the exchange of metabolites and fluid between the umbilical vessels and the amniotic cavity [19]. It is composed of an insoluble fibrillar network of different collagen types within which soluble open-coil polysaccharides are held. Of these, the most represented is hyaluronic acid, which can entrap large amounts of water. A smaller part of the Wharton's jelly extracellular matrix is formed by sulfated glycosaminoglycans, which, in turn, are linked to proteins to form proteoglycans $[6,20]$. Bankowski et al, showed that preeclampsia is accompanied by a significant increase in the ratio of sulfated glycosaminoglycans to hyaluronic acid. These findings suggest that the reduced amount of Wharton's jelly in preeclamptic women is characterized by reduced hydration due to less hyaluronic acid and more sulfated glycosaminoglycans [9]. The present study shows a significant reduction of Wharton's jelly area in the pre-eclamptic group [Table-1]. This finding is in-line with the study done by earlier observers [12, 13]. This reduction in Wharton's jelly area could be attributed to fetal starvation in the pre-eclamptic group as a result of poor maternal nutrition.

In the present study, we found a significant correlation between Wharton's Jelly area and placental weight in both groups [Graph - 1 \&2]. This indicates higher the value of Wharton's Jelly area is associated with higher the value of placental weight. This finding is similar to the Filiz et al, who reported that progressive increase in Wharton's Jelly is accompanied by an increase in placental weight [5]. Di Naro et al reported that diameters and areas of the umbilical cords changes during gestation, and these differences depend on the reduction of the amount of Wharton's Jelly [21]. The lean umbilical cords are accompanied by torsion and fibrosis of Wharton's jelly and thickening of the vascular wall which obstructs the feto-placental circulation, leading to anoxia and fetal death [22].

\section{CONCLUSION}

An important observation of the present study 
is that placental weight and WJA were significantly decreased in the pre-eclamptic group and WJA was significantly correlated with placental weight in both groups. So, pre-eclamptic pregnancy produces a negatively impact on placental weight, which consequently produces a negative impact on the jelly area and perinatal outcomes. Awareness of this correlation will be helpful in the early assessment of placental sufficiency and state of fetal well being.

\section{Conflicts of Interests: None}

\section{REFERENCES}

[1]. Teasdale F. Gestational changes in the functional structure of the human placenta in relation to foetal growth: a morphometric study. American sJournal of Obstetrics and Gynecology 1980; 137(5):560-8.

[2]. Das B, Dutta D, Chakraborthy S, Nath P. Placental morphology in hypertensive disorders of pregnancy and its correlation with fetal outcome. J Obstet Gynecol India. 1996; 46(1):40-6.

[3]. Wang HS, Hung SC, Peng ST, Huang CC, Wei HM, Guo YJ, Fu YS, Lai MC, Chen CC. Mesenchymal stem cells in the Wharton's jelly of the human umbilical cord. Stem cells. 2004 Dec 1; 22(7):1330-37.

[4]. Vizza E, Correr S, Goranova V, Heyn R, Muglia U, Papagianni V. The collagen fibrils arrangement in the Wharton's jelly of full-term human umbilical cord. Italian journal of anatomy and embryology.1995; 100:495- 501.

[5]. Filiz AA, Rahime B, Keskin HL, Esra AK. Positive correlation between the quantity of Wharton's jelly in the umbilical cord and birth weight. Taiwanese Journal of Obstetrics and Gynecology. 2011 Mar 31; 50(1):33-6.

[6]. Sobolewski K, Bankowski E, Chyczewski L et al. Collagen and glycosaminoglycans of Wharton's jelly. Biol Neonate 1997; 71:11-21.

[7]. Sakamoto T, Ono H, Saito Y. Electron microscopic histochemical studies on the localization of hyaluronic acid in Wharton's jelly of the human umbilical cord [in Japanese]. Nippon Sanka Fujinka Gakkai Zasshi 1996; 48:501- 507.

[8]. Goodlin RC. Fetal dysmaturity,"lean cord," and fetal distress. American journal of obstetrics and gynecology. 1987 May 31; 156(5):1357.

[9]. Bankowski E, Palka J, Jaworski S. Preeclampsia is associated with alterations in insulin-like growth factor (IGF)-1 and IGF-binding proteins in Wharton's jelly of the umbilical cord. Clinical chemistry and laboratory medicine. $2000 \mathrm{Jul}$ 11; 38(7):603-8.
[10]. Ali AF, Fateen B, Ezzet A, Badawy H, Ramadan A, Eltobge A. Lack of proteoglycans in Wharton's jelly of the human umbilical cord as a cause of unexplained fetal loss in diabetic infants. Obstetrics \& Gynecology. 2000 Apr 30; 95(4):S61-62.

[11]. Galewska Z, Bañkowski E, Romanowicz L, Gogiel T, Wolañska M, Jaworski S. Preeclampsia-associated reduction of cathepsin $D$ activity in the umbilical cord. Clinica chimica acta. 2005 Jan 31; 351(1):17784.

[12].Barnwal M, Rathi SK, Chhabra S, et al. Histomorphometry of umbilical cord and its vessels in pre-eclampsia as compared to normal pregnancies. Nepal Journal of Obstetrics \& Gynaecology. 2012; 7(1):28-32.

[13]. Inan S, Sanci M, Can D, et al. Comparative morphological differences between umbilical cords from chronic hypertensive and preeclamptic pregnancies. Acta Medica Okayama. 2002; 56(4):177-86.

[14]. Park K. Park's textbook of Preventive and Social Medicine. $22^{\text {nd }}$ ed. Jabalpur: M/S Banarsidas Bhanot India; 2013.

[15]. Udainia A, Jain ML. Morphological study of placenta in pregnancy induced hypertension with its clinical relevance. J Anat Soc India. 2001; 50(1):24-7.

[16]. Krishna U, Bhalerao S. Placental insufficiency and fetal growth restriction. The Journal of Obstetrics and Gynecology of India. 2011 Oct 1; 61(5):505-11.

[17]. Singh S, Gugapriya TS. A cross sectional morphometric study of hypertensive with normal placentae and its correlation with fetal outcome. Int J Anat Res. 2014; 2(2):437-42.

[18].Majumdar S, Dasgupta H, Bhattacharya K, Bhattacharya A. A study of placenta in normal and hypertensive pregnancies. J. Anat. Soc. India. 2005; 54(2):1-9.

[19]. Nanaev AK, Kohnen G, Milovanov AP, Domogatsky SP, Kaufmann P. Stromal differentiation and architecture of the human umbilical cord. Placenta. 1997 Jan 31; 18(1):53-64.

[20]. Klein J, Meyer FA. Tissue structure and macromolecular diffusion in umbilical cord immobilization of endogenous hyaluronic acid. Biochimica et Biophysica Acta (BBA)-General Subjects. 1983 Feb 22; 755(3):400-11.

[21]. Di Naro E, Ghezzi F, Raio L, Franchi M, D’Addario V. Umbilical cord morphology and pregnancy outcome. European Journal of Obstetrics \& Gynecology and Reproductive Biology. 2001 Jun 30; 96(2):150-157.

[22]. Tavares FJ, Lourdes PM. Coarctation of the umbilical cord: a cause of intrauterine fetal death. International journal of gynaecology and obstetrics: the official organ of the International Federation of Gynaecology and Obstetrics. 1977; 15(5):469-73. 